\title{
DFT Treatment of ANTA and Some of its Tautomers
}

\section{Lemi Türker}

Department of Chemistry, Middle East Technical University, Üniversiteler, Eskişehir Yolu No: 1, 06800 Çankaya/Ankara, Turkey; e-mail: 1turker@gmail.com; lturker@metu.edu.tr

\section{Abstract}

An insensitive explosive material, ANTA, and some of its prototropic tautomers have been considered within the constraints of density functional theory at the levels of B3LYP/6-311++G(d,p) and B3LYP/cc-PVTZ (partly). Various energetic, quantum chemical and spectral properties have been obtained and discussed. The NICS $(0)$ values have been obtained and contemplated on them.

\section{Introduction}

Chemically 5-amino-3-nitro-1H-1,2,4-triazole (also named as 3-amino-5-nitro-1H1,2,4-triazole) has the abbreviated name, ANTA or ANT which is a very insensitive explosive molecule [1]. The material is very insensitive to impact and moderately so to thermal stimuli. Performance was found to be inferior to 1,3,5-triamino-2,4,6trinitrobenzene (TATB). Its synthesis was achieved decades ago by many researchers [24]. The synthesis having high yield [3] made use of selective reduction of 3,5-dinitro- $1 \mathrm{H}-$ 1,2,4-triazole (DNT), which was prepared from 3,5-diamino-1H-1.2,4-triazole and isolated as the ammonium salt (ADNT). Selective reduction of ADNT with hydrazine hydrate gave the hydrazinium salt of ANTA (HANTA), which was acidified in situ to consistently give greater than $90 \%$ yields of pure ANTA.

In addition to its potential use as an insensitive high explosive, ANTA has been shown to be a useful intermediate for the preparation of other explosives [2]. A computational study has been published on ANTA [5]. The effect of electric field on

Received: March 24, 2021; Accepted: April 24, 2021

Keywords and phrases: ANTA, ANT, 3-amino-5-nitro-1,2,4-triazole, explosive, tautomerism, NICS.

Copyright (C) 2021 Lemi Türker. This is an open access article distributed under the Creative Commons Attribution License, which permits unrestricted use, distribution, and reproduction in any medium, provided the original work is properly cited. 
ANTA has been reported recently [6].

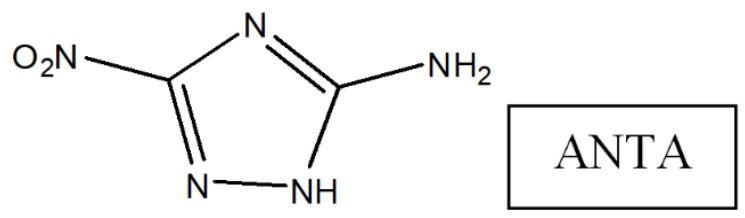

In the present study, ANTA and some of its prototropic tautomers are considered within the restrictions of density functional theory (DFT).

\section{Method of Calculations}

The initial geometry optimizations of all the structures leading to energy minima were achieved by using MM2 method followed by semi-empirical PM3 self-consistent fields molecular orbital (SCF MO) method [7,8] at the restricted level [9]. Then, the structure optimizations have been achieved within the framework of Hartree-Fock (HF) and finally by using density functional theory (DFT) at the levels of and B3LYP/6$31++G(d, p)$ and B3LYP/CC-PVTZ $[10,11]$. Note that the exchange term of B3LYP consists of hybrid Hartree-Fock and local spin density (LSD) exchange functions with Becke's gradient correlation to LSD exchange [12]. The correlation term of B3LYP consists of the Vosko, Wilk, Nusair (VWN3) local correlation functional [13] and Lee, Yang, Parr (LYP) correlation correction functional [14]. The normal mode analysis for each structure yielded no imaginary frequencies for the $3 N-6$ vibrational degrees of freedom, where $N$ is the number of atoms in the system. This indicates that the structure of each molecule corresponds to at least a local minimum on the potential energy surface. Furthermore, all the bond lengths were thoroughly searched in order to find out whether any bond cleavage occurred or not during the geometry optimization process. All these computations were performed by using SPARTAN 06 [15]. For the NICS calculations Gaussian 03 program was employed [16].

\section{Results and Discussion}

Instances in chemistry are known that substances which are isomeric under certain given conditions are tautomeric under more drastic conditions [17]. Although, ANTA has just three hydrogens, it has various sites for those hydrogens to undergo tautomeric transformations (cationotropic type, prototropic transformation). Figure 1 shows the optimized structures of 1,3 and 1,5-type proton tautomers of ANTA. The abbreviations, 
$1,3 \mathrm{a}$ and $1,3 \mathrm{~b}$ or $1,5 \mathrm{a}$ and $1,5 \mathrm{~b}$ stand for different forms 1,3 or 1,5-types of them. The figure also shows the direction of dipole moment vector of each specie. Some of these tautomers have $6 \pi$-electons in a cyclic conjugation and are expected to be aromatic (see the NICS section below).

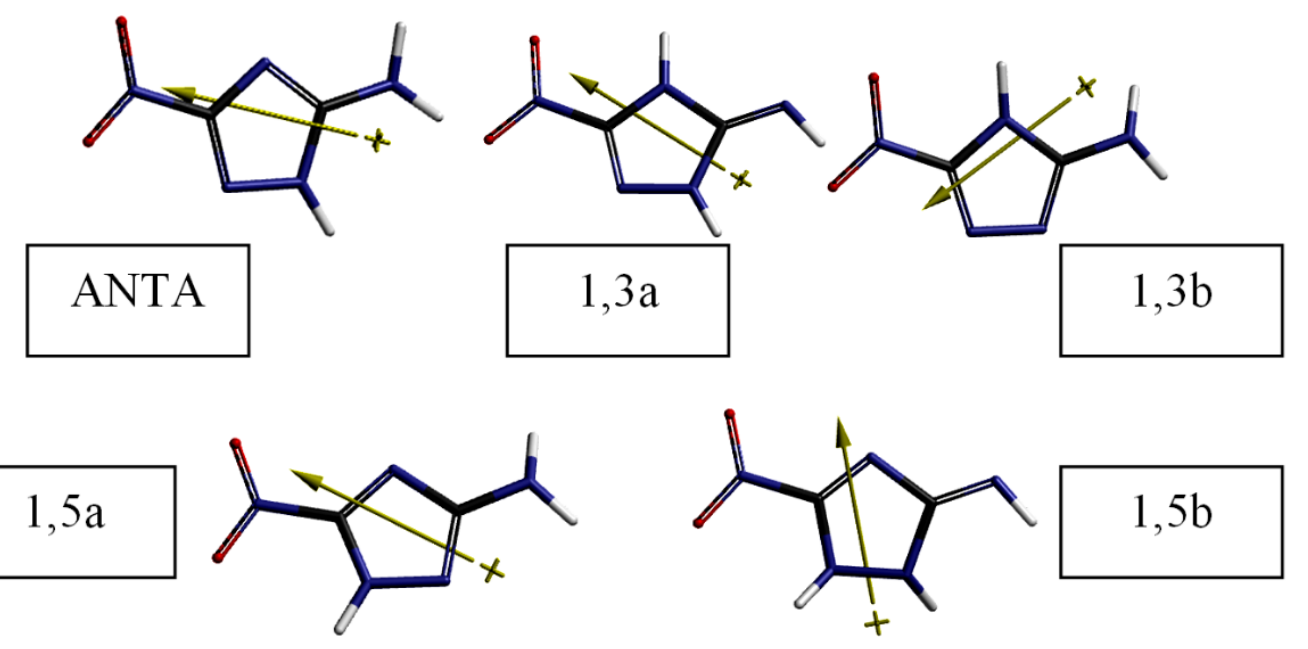

Figure 1. Optimized structures of the present concern (B3LYP/6-311++G(d,p)).

In the IR spectrum of ANTA (B3LYP/6-311++G(d,p)), asymmetric and symmetrical $\mathrm{NH}_{2}$ stretchings occur at 3670 and $3569 \mathrm{~cm}^{-1}$, respectively. Whereas the N-H stretching happens at $3634 \mathrm{~cm}^{-1}$. The ring N-H stretchings of 1,3a appear at 3660 and $3663 \mathrm{~cm}^{-1}$. On the other hand, the imino hydrogen stretches at $3542 \mathrm{~cm}^{-1}$. The IR spectrum of $1,3 \mathrm{~b}$ is similar in many respects to spectrum of ANTA. The asymmetric and symmetrical $\mathrm{NH}_{2}$ stretchings occur at 3659 and $3559 \mathrm{~cm}^{-1}$, respectively. Whereas the ring $\mathrm{N}-\mathrm{H}$ stretching occurs at $3628 \mathrm{~cm}^{-1}$. In the case of 1,5a tautomer stretchings occurring at 3694, 3637 and $3584 \mathrm{~cm}^{-1}$ stand for the asymmetric $\mathrm{NH}_{2}$, the $\mathrm{N}-\mathrm{H}$ stretching of the ring and symmetrical $\mathrm{NH}_{2}$ stretching, respectively. Tautomer $1,5 \mathrm{~b}$ has the ring N-H stretchings at 3542 and $3532 \mathrm{~cm}^{-1}$ whereas the imino N-H stretching occurs at $3501 \mathrm{~cm}^{-1}$.

Tables 1 and 2 show some energies of the tautomers presently considered at the levels of B3LYP/6-311++G(d,p) and B3LYP/cc-PVTZ level, respectively. In the tables, $\mathrm{E}, \mathrm{ZPE}$ and $\mathrm{E}_{\mathrm{C}}$ stand for the total electronic energy, zero point vibrational energy and the corrected total electronic energy, respectively. At both levels of calculations the electronic stability order is $1,5 \mathrm{a}>$ ANTA $>1,5 \mathrm{~b}>1,3 \mathrm{~b}>1,3 \mathrm{a}$. Note that $1,5 \mathrm{a}$ tautomer is much more stable than $1,5 \mathrm{~b}$ at both level of calculations. 
Table 1. Some energies of the structures considered.

\begin{tabular}{lccc}
\hline Structure & $\mathbf{E}$ & $\mathbf{Z P E}$ & $\mathbf{E}_{\mathbf{C}}$ \\
\hline ANTA & -1318666.57 & 206.01 & -1318460.56 \\
$1,3 \mathrm{a}$ & -1318615.62 & 203.90 & -1318411.72 \\
$1,3 \mathrm{~b}$ & -1318643.00 & 204.42 & -1318438.58 \\
$1,5 \mathrm{a}$ & -1318671.51 & 206.35 & -1318465.16 \\
$1,5 \mathrm{~b}$ & -1318547.60 & 204.88 & -1318342.72 \\
\hline
\end{tabular}

Energies in $\mathrm{kJ} / \mathrm{mol}$. B3LYP/6-311++G(d,p) level.

Table 2. Some energies of the structures considered.

\begin{tabular}{lccc}
\hline Structure & $\mathbf{E}$ & $\mathbf{Z P E}$ & $\mathbf{E}_{\mathbf{C}}$ \\
\hline ANTA* & -1318765.25 & 206.27 & -1318558.98 \\
$1,3 \mathrm{a}^{*}$ & -1318716.69 & 204.21 & -1318512.48 \\
$1,3 \mathrm{~b}^{*}$ & -1318744.65 & 205.06 & -1318539.59 \\
$1,5 \mathrm{a}^{*}$ & -1318771.85 & 207.02 & -1318564.83 \\
$1,5 \mathrm{~b}^{*}$ & -1318649.29 & 205.13 & -1318444.16 \\
\hline
\end{tabular}

Energies in kJ/mol. * B3LYP/cc-PVTZ level.

Table 3 shows some thermodynamic properties of the tautomers at the standard state. According to the data, all the structures have exothermic heat of formation $\left(\mathrm{H}^{\circ}\right)$ values and favorable Gibbs free energy of formation $\left(\mathrm{G}^{\circ}\right)$ values. The order of $\mathrm{G}^{\mathrm{o}}$ values is $1,5 \mathrm{a}$ $>$ ANTA $>1,3 \mathrm{~b}>1,3 \mathrm{a}>1,5 \mathrm{~b}$. It is worth mentioning that $1,5 \mathrm{a}$ has much more favorable $\mathrm{G}^{\mathrm{o}}$ value than $1,5 \mathrm{~b}$.

Table 3. Some thermodynamic properties of the structures considered.

\begin{tabular}{lccc}
\hline \multicolumn{1}{c}{ Structure } & $\mathbf{H}^{\mathbf{0}}$ & $\mathbf{S}^{\mathbf{0}}\left(\mathbf{J} / \mathbf{m o l}^{\mathbf{0}}\right)$ & $\mathbf{G}^{\mathbf{0}}$ \\
\hline ANTA & -1318452.153 & 347.46 & -1318555.748 \\
$1,3 \mathrm{a}$ & -1318403.457 & 346.44 & -1318506.751 \\
$1,3 \mathrm{~b}$ & -1318430.185 & 347.21 & -1318533.707 \\
$1,5 \mathrm{a}$ & -1318457.039 & 345.40 & -1318560.02 \\
$1,5 \mathrm{~b}$ & -1318335.157 & 343.48 & -1318437.568 \\
\hline
\end{tabular}

Energies in kJ/mol. B3LYP/6-311++G(d,p) level. 
Tautomer 1,5a has more favorable energy characteristics over ANTA because a fivemembered hydrogen bridge is possible in it (with $\mathrm{NO}_{2}$ group) as seen in the following scheme. Whereas in ANTA structure a hydrogen bridge between the $\mathrm{NH}_{2}$ group and ring hydrogen leads to a four-membered ring which is not a so favorable situation.
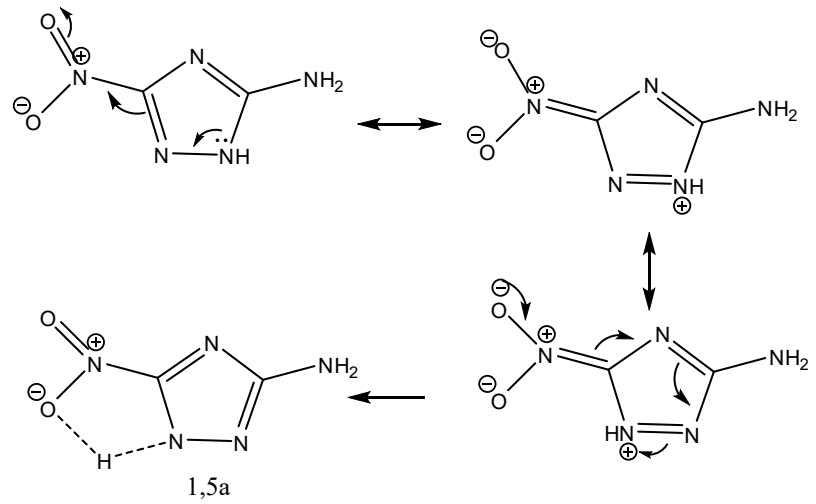

Table 4 displays some properties of the tautomers of the present interest. In the table ANTA and 1,3b are noticeable with relatively higher dipole moment values but equal $\log \mathrm{P}$.

Figure 2 shows the electrostatic potential (ESP) maps of the tautomers considered which are based on the ESP charges. Note that the ESP charges are obtained by the program based on a numerical method that generate charges that reproduce the electrostatic potential field from the entire wavefunction [15]. As seen in the figure, the tautomerism in these structures not only changes the direction of the dipole moment vectors but also intensities of the positive and negative potential regions because in each case reshuffling of the $\sigma$ - and $\pi$-electron distributions occur.

Table 4. Some properties of the tautomeric structures considered.

\begin{tabular}{lcccc} 
Structure & Aqueous Energy & Polarizability & Log P & $\begin{array}{c}\text { Dipole } \\
\text { (Debye) }\end{array}$ \\
\hline ANTA & -1318744.09 & 48.22 & 0.56 & 8.42 \\
$1,3 \mathrm{a}$ & -1318668.60 & 48.58 & 0.84 & 3.73 \\
$1,3 \mathrm{~b}$ & -1318695.15 & 48.36 & 0.56 & 7.25 \\
$1,5 \mathrm{a}$ & -1318726.54 & 48.47 & 0.56 & 3.91 \\
$1,5 \mathrm{~b}$ & -1318617.23 & 48.59 & 0.84 & 5.62 \\
\hline
\end{tabular}

Energies in $\mathrm{kJ} / \mathrm{mol}$. B3LYP/6-311++G(d,p) level. 

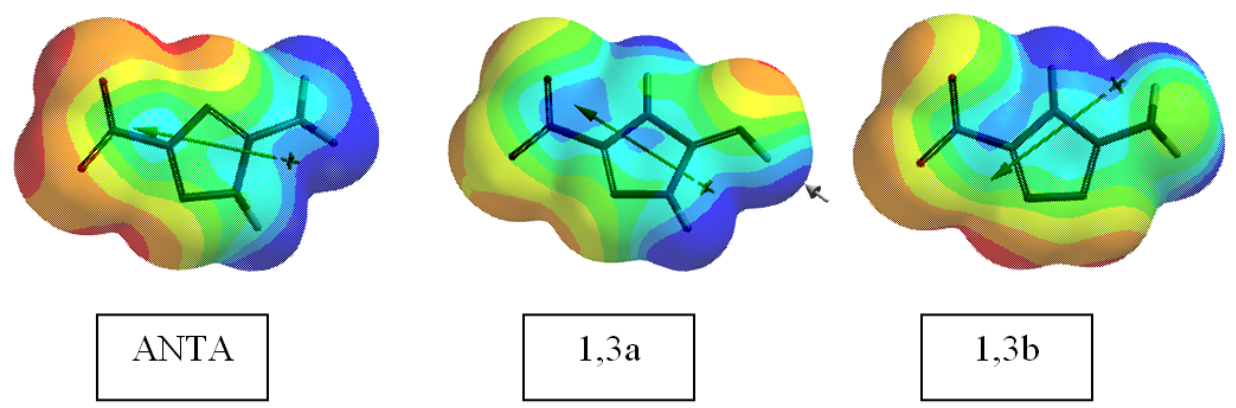

\section{$1,3 b$}
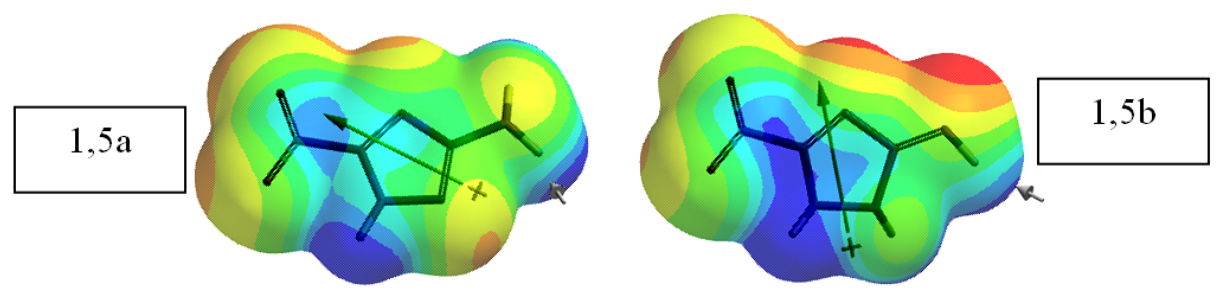

Figure 2. Electrostatic potential maps of the tautomers considered (B3LYP/6$311++\mathrm{G}(\mathrm{d}, \mathrm{p})$ level).

Figure 3 displays some of the molecular orbital energy levels of the structures considered. ANTA, 1,3b and 1,5a differ only by the position of ring hydrogen. Whereas in the case of 1,3a and 1,5b-tautomers the amino substituent is involved in the proton transfer process.

Table 5 shows the HOMO, LUMO energies and $\Delta \varepsilon$ values of the tautomers considered. Note that $\Delta \varepsilon$ (interfrontier molecular orbital energy gap) is $\varepsilon_{\mathrm{LUMO}}-\varepsilon_{\mathrm{HOMO}}$. The HOMO energy order is ANTA $<1,3 \mathrm{~b}<1,5 \mathrm{~b}<1,5 \mathrm{a}<1,3 \mathrm{a}$ whereas the energy order for LUMOs is $1,5 \mathrm{~b}<1,3 \mathrm{a}<1,5 \mathrm{a}<1,3 \mathrm{~b}<$ ANTA. Consequently, $\Delta \varepsilon$ values fall in to the order of $1,3 \mathrm{a}<1,5 \mathrm{~b}<1,5 \mathrm{a}<1,3 \mathrm{~b}<$ ANTA.

The narrowing of interfrontier molecular orbital (FMO) gap indicates that of the tautomers presently considered, ANTA should be least sensitive whereas 1,3a is the most sensitive ones to impact stimuli because $\Delta \varepsilon$ values are related to impact sensitivity in explosives $[18,19]$. Namely, as the FMO energy gap $(\Delta \varepsilon)$ becomes less and less the impact sensitivity increases more and more.

Figure 4 shows the time-dependent density functional UV-VIS spectra of the tautomers presently considered. ANTA and 1,3b spectra are similar to each other, both are confined to ultraviolet region having some small shift of $\lambda_{\max }$ and intensity values. 
The rest of the spectra have some bathochromic shift to visible region because they have all smaller interfrontier molecular orbital energy gap values than the respective values of ANTA and 1,3b-tautomer.
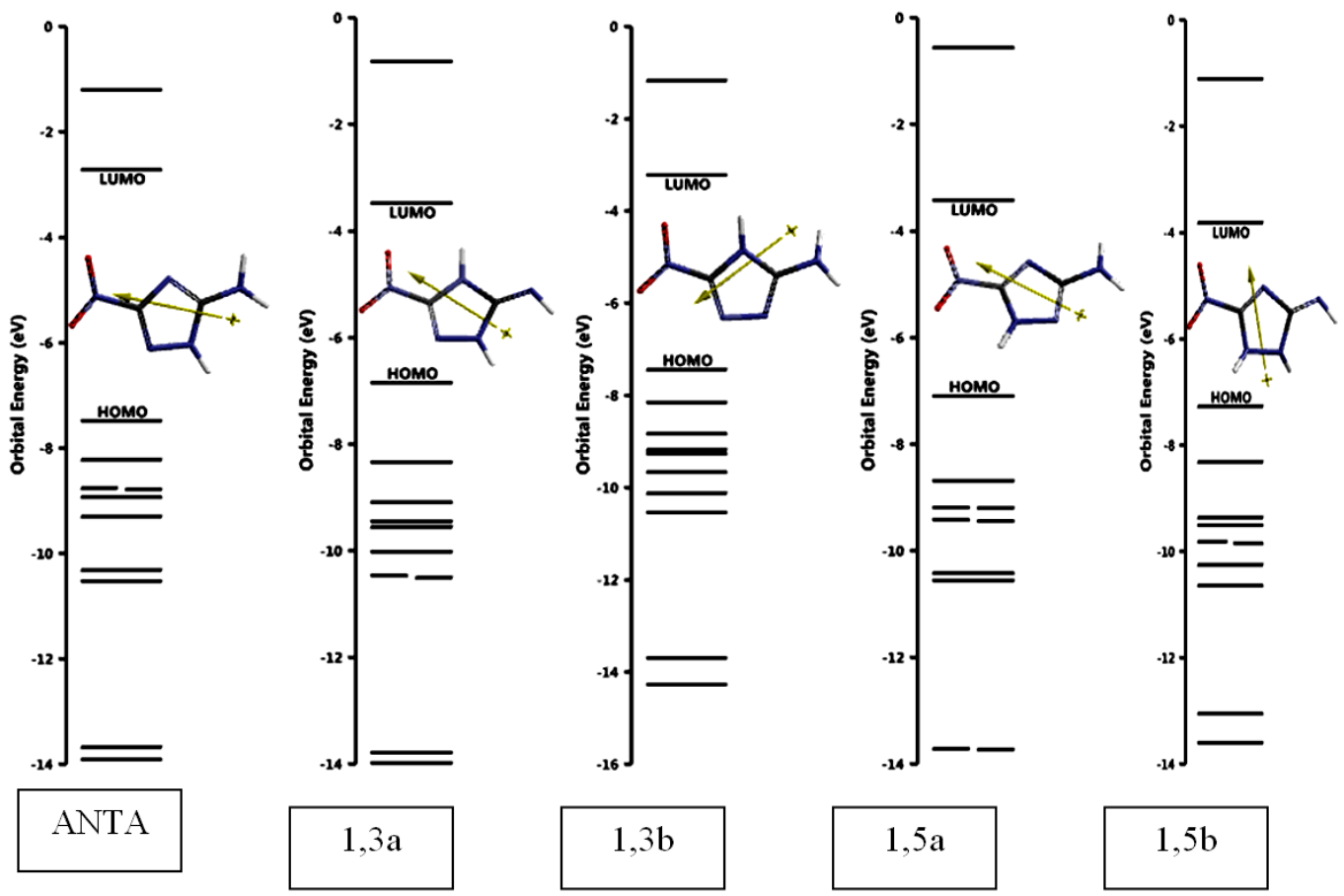

Figure 3. Some of the molecular orbital energy levels of the structures considered (B3LYP/6-311++G(d,p)).

Table 5. The HOMO, LUMO energies and $\Delta \varepsilon$ values of the tautomers considered.

\begin{tabular}{lccc}
\hline \multicolumn{1}{c}{ Structure } & HOMO & LUMO & $\Delta \boldsymbol{\varepsilon}$ \\
\hline ANTA & -722.18 & -261.43 & 460.75 \\
$1,3 \mathrm{a}$ & -660.50 & -335.13 & 325.37 \\
$1,3 \mathrm{~b}$ & -717.42 & -310.19 & 407.23 \\
$1,5 \mathrm{a}$ & -684.54 & -330.53 & 354.01 \\
$1,5 \mathrm{~b}$ & -701.50 & -368.26 & 333.24 \\
\hline
\end{tabular}

Energies in kJ/mol. B3LYP/6-311++G(d,p) level. 

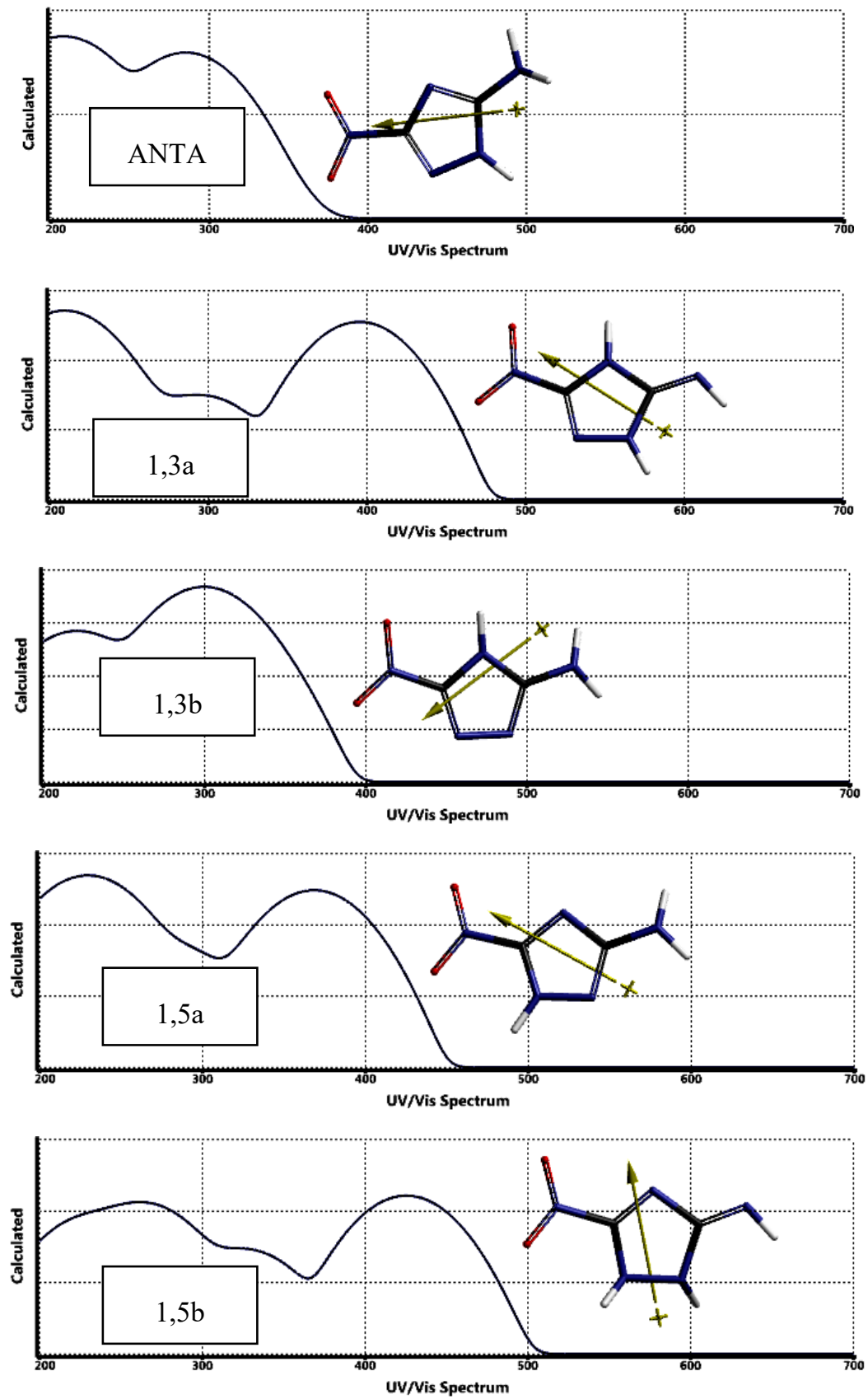

Figure 4. Time-dependent UV-VIS spectra of the tautomers (B3LYP/6-311++G(d,p) level).

Figure 5 shows the local ionization potential maps of the structures considered. In a 
local ionization potential map conventionally red regions on the density surface indicate areas from which electron removal is relatively easy, meaning that they are subject to electrophilic attack. On the other hand, regions having blue color represent areas where ionization is relatively difficult. Hence, in these structures electron removal is relatively easy from regions colored in yellow/yellowish.
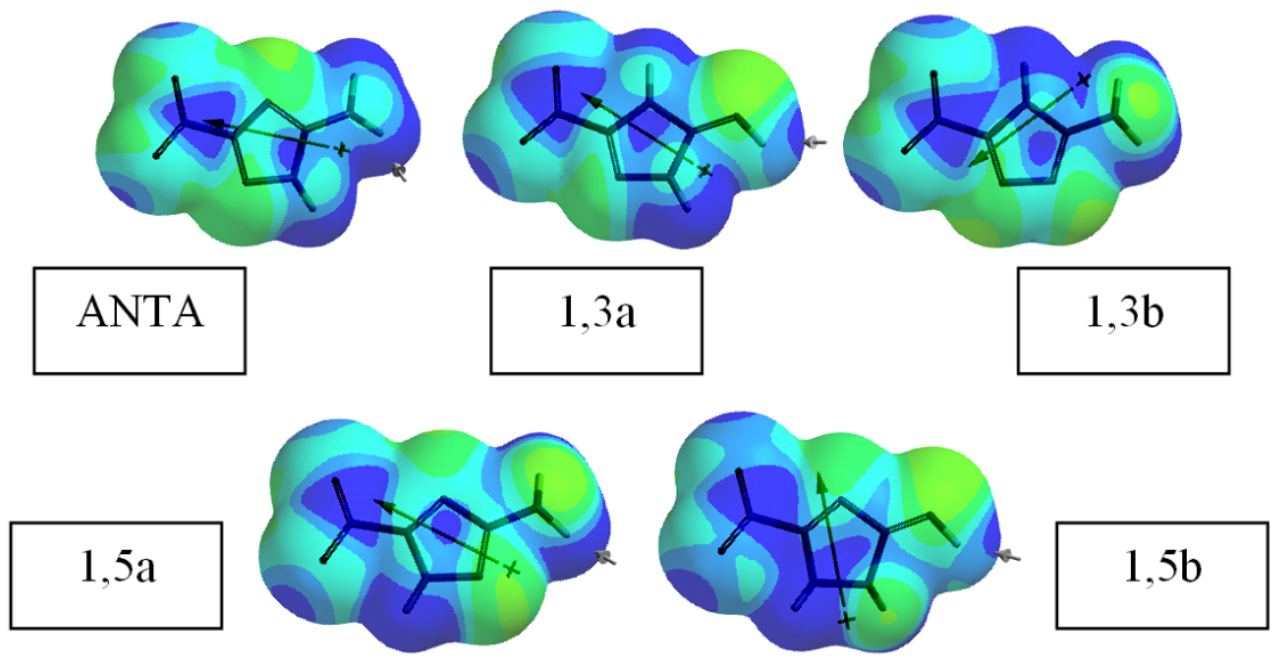

Figure 5. The local ionization maps of the tautomers considered (B3LYP/6$311++\mathrm{G}(\mathrm{d}, \mathrm{p}))$.
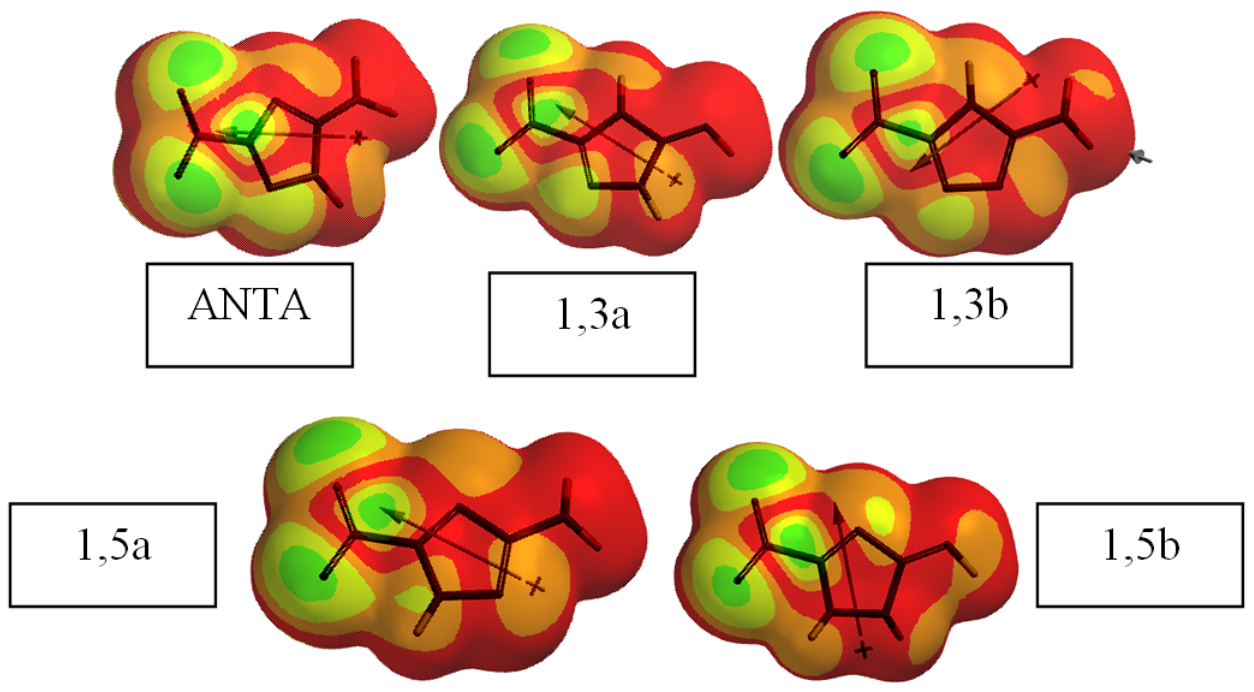

Figure 6. The LUMO maps of the tautomers considered (B3LYP/6-311++G(d,p)). 
Figure 6 shows the LUMO maps of the tautomers considered. A LUMO map displays the absolute value of the LUMO on the electron density surface. The blue color stands for the maximum value of the LUMO and the color red, the minimum value. Hence, a nucleophile attacks on the atom having the blue color. Hence, green regions in the present are relatively more susceptible to nucleophilic attack.

\section{NICS}

Aromaticity arises by a combination of various properties in cyclic delocalized systems. In the literature, generally aromaticity has been discussed in terms of energetic, structural and magnetic criteria. [20-25]. In 1996, Schleyer has introduced a simple but efficient probe for aromaticity that is "nucleus-independent chemical shift" (NICS) [26]. It is the computed value of the negative magnetic shielding at some selected point in space which is generally, at a ring or cage center. The calculated data piled in the literature through the years indicate that negative NICS values denote aromaticity (-11.5 for benzene, -11.4 for naphthalene) whereas positive NICS values denote antiaromaticity (28.8 for cyclobutadiene) while small NICS values indicate non-aromaticity $(-2.1$ for cyclohexane, -1.1 for adamantane). NICS may be a useful indicator of aromaticity that usually correlates successfully with the other energetic, structural and magnetic criteria for aromaticity [27-30]. Resonance energies and magnetic susceptibilities measure the overall aromaticity of a polycycle, but do not provide any information about the individual rings. In contrast, NICS has been proved to be an effective probe for local aromaticity of individual rings of polycyclic systems.

Table 6 shows the NICS $(0)$ values of the aromatic tautomers of ANTA. Those structures have cyclic conjugation of $6 \pi$-electrons whereas the other tautomers considered do not. According to the data displayed there the order of NICS values is ANTA $>1,5 \mathrm{a}>$ 1,3b. Note that all of the aromatic tautomers have $\mathrm{NO}_{2}$ and $\mathrm{NH}_{2}$ groups which are electron withdrawal and electron donating groups, respectively. However, they are located such that in ANTA and 1,5a they cannot exert pull-push action (from $\mathrm{NO}_{2}$ to $\mathrm{NH}_{2}$ groups) whereas in 1,3b they can. Thus, due to the pull-push action of these groups in $1,3 \mathrm{~b}$-structure the cyclic $6 \pi$-electron conjugation is somewhat disturbed. Consequently, $1,3 \mathrm{~b}$-structure possesses the lowest NICS value (in absolute value) among them. In ANTA and 1,5a structures, cyclic $6 \pi$-electron conjugation is just under the influence of less pronounced electronic effects originating from the $\pi$ - and/or $\sigma$-skeletons. 
Table 6. NICS values of the aromatic tautomers.

\begin{tabular}{cccc}
\hline Structure & ANTA & $\mathbf{1 , 3 b}$ & $\mathbf{1 , 5 a}$ \\
\hline NICS & -11.2577 & -9.4615 & -10.8660 \\
\hline
\end{tabular}

B3LYP/6-311++G(d,p)

\section{Conclusion}

The present density functional treatise has revealed that among the various 1,3 and 1,5 tautomers originated from ANTA structure, 1,5a-tautomer in vacuum conditions is electronically more stable and at the standard state thermally more favorable than ANTA. However, NICS $(0)$ values indicate that ANTA has more aromatic character than $1,5 \mathrm{a}$ tautomer. Moreover, the aqueous energy of ANTA is more stabilizing than 1,5a. On the other hand, the calculations predict that ANTA is less sensitive to impact stimulus than the other tautomers.

\section{References}

[1] J.P. Agrawal, High Energy Materials, Weinheim: Wiley-VCH, 2010. https://doi.org/10.1002/9783527628803

[2] K.Y. Lee, C.B. Storm, M.A. Hiskey and M.D. Coburn, An improved synthesis of 5amino-3-nitro-1H-1,2,4-triazole (ANTA), a useful intermediate for the preparation of insensitive high explosives, J. Energ. Mat. 9(5) (1991), 415-428. https://doi.org/10.1080/07370659108019382

[3] R.L. Simpson, P.F. Pagoria, A.R. Mitchell and C.L. Coon, Synthesis, properties and performance of the high explosive ANTA, Prop. Explos. Pyrotech. 19 (1994), 174-179. https://doi.org/10.1002/prep.19940190405

[4] T.D. Manship, D.M. Smith and D.G. Piercey, An improved synthesis of the insensitive energetic material 3-amino-5-nitro-1,2,4-triazole (ANTA), Prop. Explos. Pyrotech. 45(10) (2020), 1621-1626. https://doi.org/10.1002/prep.202000097

[5] J.F. Moxnes, Ø. Frøyland and T. Risdal, A computational study of ANTA and NTO derivatives, Journal of Molecular Modeling 23(8) (2017), 240. https://doi.org/10.1007/s00894-017-3408-7

[6] L. Türker, Effect of electric field on anta, Earthline Journal of Chemical Sciences 5(2) (2021), 329-345. https://doi.org/10.34198/ejcs.5221.329345 
[7] J.J.P. Stewart, Optimization of parameters for semi empirical methods I, J. Comput. Chem. 10 (1989), 209-220. https://doi.org/10.1002/jcc.540100208

[8] J.J.P. Stewart, Optimization of parameters for semi empirical methods II, J. Comput. Chem. 10 (1989), 221-264. https://doi.org/10.1002/jcc.540100209

[9] A.R. Leach, Molecular Modeling, Essex: Longman, 1997.

[10] W. Kohn and L.J. Sham, Self-consistent equations including exchange and correlation effects, Phys. Rev. 140 (1965), 1133-1138. https://doi.org/10.1103/PhysRev.140.A1133

[11] R.G. Parr and W. Yang, Density Functional Theory of Atoms and Molecules, London: Oxford University Press, 1989.

[12] A.D. Becke, Density-functional exchange-energy approximation with correct asymptotic behavior, Phys. Rev. A 38 (1988), 3098-3100. https://doi.org/10.1103/PhysRevA.38.3098

[13] S.H. Vosko, L. Wilk and M. Nusair, Accurate spin-dependent electron liquid correlation energies for local spin density calculations: a critical analysis, Can. J. Phys. 58 (1980), 1200-1211. https://doi.org/10.1139/p80-159

[14] C. Lee, W. Yang and R.G. Parr, Development of the Colle-Salvetti correlation-energy formula into a functional of the electron density, Phys. Rev. B 37 (1988), 785-789. https://doi.org/10.1103/PhysRevB.37.785

[15] SPARTAN 06, Wavefunction Inc., Irvine CA, USA, 2006.

[16] M.J. Frisch, G.W. Trucks, H.B. Schlegel, G.E. Scuseria, M.A. Robb, J.R. Cheeseman, J.A. Montgomery, Jr., T. Vreven, K.N. Kudin, J.C. Burant, J. M. Millam, S. S. Iyengar, J. Tomasi, V. Barone, B. Mennucci, M. Cossi, G. Scalmani, N. Rega, G.A. Petersson, H. Nakatsuji, M. Hada, M. Ehara, K. Toyota, R. Fukuda, J. Hasegawa, M. Ishida, T. Nakajima, Y. Honda, O. Kitao, H. Nakai, M. Klene, X. Li, J. E. Knox, H. P. Hratchian, J.B. Cross, V. Bakken, C. Adamo, J. Jaramillo, R. Gomperts, R.E. Stratmann, O. Yazyev, A.J. Austin, R. Cammi, C. Pomelli, J.W. Ochterski, P.Y. Ayala, K. Morokuma, G.A.Voth, P. Salvador, J.J. Dannenberg, V.G. Zakrzewski, S. Dapprich, A.D. Daniels, M.C.Strain, O. Farkas, D.K. Malick, A.D. Rabuck, K. Raghavachari, J.B. Foresman, J.V. Ortiz, Q. Cui, A.G. Baboul, S. Clifford, J. Cioslowski, B.B. Stefanov, G. Liu, A. Liashenko, P. Piskorz, I. Komaromi, R.L. Martin, D.J. Fox, T. Keith, M.A. Al-Laham, C.Y. Peng, A. Nanayakkara, M. Challacombe, P.M. W. Gill, B. Johnson, W. Chen, M.W. Wong, C. Gonzalez and J.A. Pople, Gaussian, Inc., Wallingford CT, 2004.

[17] O. Reutov, Theoretical Principles of Organic Chemistry, Moscow: Mir Pub, 1970. 
[18] V. Anbu, K.A. Vijayalakshmi, R. Karunathan, A.D. Stephen and P.V. Nidhin, Explosives properties of high energetic trinitrophenyl nitramide molecules: A DFT and AIM analysis, Arabian Journal of Chemistry 12(5) (2019), 621-632.

https://doi.org/10.1016/j.arabjc.2016.09.023

[19] N.R. Badders, C. Wei, A.A. Aldeeb, W.J. Rogers and M.S. Mannan, Predicting the impact sensitivities of polynitro compounds using quantum chemical descriptors, Journal of Energetic Materials 24 (2006), 17-33. https://doi.org/10.1080/07370650500374326

[20] V.I. Minkin, M.N. Glukhovtsev and B.Y. Simkin, Aromaticity and Antiaromaticity: Electronic and Structural Aspects, New York: Wiley, 1994.

[21] P.R. Schleyer and H. Jiao, What is aromaticity?, Pure Appl. Chem. 68 (1996), 209-218. DOI: https://doi.org/10.1351/pac199668020209

[22] M.N. Glukhovtsev, Aromaticity today: energetic and structural criteria, J. Chem Educ. 74 (1997), 132-136. https://doi.org/10.1021/ed074p132

[23] T.M. Krygowski, M.K. Cyranski, Z. Czarnocki, G. Hafelinger and A.R. Katritzky, Aromaticity: a theoretical concept of immense practical importance, Tetrahedron 56 (2000), 1783-1796. https://doi.org/10.1016/S0040-4020(99)00979-5

[24] P.R. Schleyer, Introduction: Aromaticity, Chem Rev. 101 (2001), 1115-1118. https://doi.org/10.1021/cr0103221

[25] M.K. Cyranski, T.M. Krygowski, A.R. Katritzky and P.R. Schleyer, To what extent can aromaticity be defined uniquely?, J. Org. Chem. 67 (2002), 1333-1338. https://doi.org/10.1021/jo016255s

[26] P.R. Schleyer, C. Maerker, A. Dransfeld, H. Jiao and N.J.R.E. Hommes, Nucleusindependent chemical shifts: A simple and efficient aromaticity probe, J. Am. Chem. Soc. 118 (1996), 6317-6318. doi: 10.1021/ja960582d.

[27] H. Jiao and P.R. Schleyer, Aromaticity of pericyclic reaction transition structures: magnetic evidence, J. Phys. Org. Chem. 11 (1998), 655-662.

https://doi.org/10.1002/(SICI)1099-1395(199808/09)11:8/9<655::AID-POC66>3.0.CO;2U

[28] P.R. Schleyer, B. Kiran, D.V. Simion and T.S. Sorensen, Does $\mathrm{Cr}(\mathrm{CO}) 3$ complexation reduce the aromaticity of benzene?, J. Am. Chem. Soc. 122 (2000), 510-513. https://doi.org/10.1021/ja9921423

[29] D. Quinonero, C. Garau, A. Frontera, P. Ballaster, A. Costa and P.M. Deya, Quantification of aromaticity in oxocarbons: The problem of the fictitious "nonaromatic" reference system, Chem. Eur. J. 8 (2002), 433-438.

https://doi.org/10.1002/1521-3765(20020118)8:2<433::AID-CHEM433>3.0.CO;2-T 
[30] S. Patchkovskii and W. Thiel, Nucleus-independent chemical shifts from semiempirical calculations, J. Mol. Model. 6 (2002), 67-75. https://doi.org/10.1007/PL00010736. 